\title{
Art and artistic processes bridge knowledge systems about social-ecological change: An empirical examination with Inuit artists from Nunavut, Canada
}

\author{
Kaitlyn J. Rathwell $^{1,2}$ and Derek Armitage ${ }^{1}$
}

\begin{abstract}
The role of art and artistic processes is one fruitful yet underexplored area of social-ecological resilience. Art and art making can nurture Indigenous knowledge and at the same time bridge knowledge across generations and cultures (e.g., Inuit and scientific). Experiences in two Inuit communities in northern Canada (Cape Dorset and Pangnirtung, Nunavut) provide the context in which we empirically examine the mechanisms through which art and art making may bridge knowledge systems about socialecological change. Art making and artworks create continuity between generations via symbols and skill development (e.g., seal skin stretching for a modern artistic mural) and by creating mobile and adaptive boundary objects that function as a shared reference point to connect different social worlds. Our results indicate how art and artistic processes may bridge knowledge systems through six mechanisms, and in so doing contribute to social-ecological resilience during change and uncertainty. These mechanisms are (1) embedding knowledge, practice and belief into art objects; (2) sharing knowledge using the language of art; (3) sharing of art making skills; (4) art as a contributor to monitoring social-ecological change; (5) the role of art in fostering continuity through time; and (6) art as a site of knowledge coproduction.
\end{abstract}

Key Words: Arctic; art; bridging knowledge systems; knowledge integration; knowledge systems; resilience; social-ecological change; traditional ecological knowledge

\section{INTRODUCTION}

In this paper we examine the role of art and artistic processes as an increasingly important context in which to bridge knowledge systems, or ways of knowing, about social-ecological change. We situated our study in the context of the Canadian Arctic, where rapidly changing sea ice conditions and climate change make the need to bridge knowledge systems an important priority (ACIA 2005, Arctic Council 2013). Connecting ways of knowing, such as scientific and Indigenous ways of knowing, is argued to play a key role in fostering collaborative governance and community adaptation, and in enhancing overall understandings of, and responses to, environmental change (Mitchell et al. 2006, Reid et al. 2006). Art and artistic processes can make a valuable and unique contribution to nurturing Indigenous knowledge and bridging that knowledge with other ways of knowing (Zurba and Berkes 2014, Zurba and Friesen 2014, Rathwell et al. 2015).

Knowledge systems are complex and dynamic socialpsychological structures that give meaning to the human experience (Foucault 1991, Godfrey Smith 2003, Dryzek 2005). Knowledge is dynamic and coconstructed, and can change over time as new information about the environment is gathered or observed and, subsequently, made sense of by individuals and communities (Carolan 2005, Berkes and Turner 2006). Being able to bridge knowledge systems is recognized as playing a critical role in helping to enhance resilience from local to global levels (Reid et al. 2006, Fazey et al. 2013, Gómez-Baggethun et al. 2013). There are now also international and national legal mandates to better promote and protect Indigenous knowledge (UN 2007, Koutouki et al. 2015). Connecting ways of knowing to create novel insights about complex environmental change while also maintaining the integrity of those knowledge systems, termed bridging knowledge systems, is an increasingly important area of applied research (Tengö et al. 2012, Thaman et al. 2013, Rathwell et al. 2015).
Many potential settings exist to bridge knowledge systems (McCarter et al. 2014, Rathwell et al. 2015). Popular techniques within an environmental change and natural resource governance context include processes such as mapping, hunting trips (Krupnik et al. 2010), creation of databases (McCarter et al. 2014), codevelopment of tools or toolkits, e.g., mobile geospatial devices (Gearheard et al. 2012), and local governance structures such as comanagement boards (Armitage et al. 2011). Choosing appropriate strategies and settings to bridge knowledge can help avoid pitfalls associated with extractive techniques (Nadasdy 2003) or superficial engagement (Leduc 2011, Weiss et al. 2013, Gratani et al. 2014). Developing strategies that can engage with and nurture existing knowledge systems (e.g., as pockets of local resilience; Barthel et al. 2013, Ruiz-Mallén and Corbera 2013) and at the same time, bridge them in ways that allow for hybrid knowledge to emerge is a significant challenge (Tengö et al. 2012, Thaman et al. 2013).

One setting that holds particular promise, which is the focus of our study, involves art and artistic processes (see also Maffie 2009, Zurba and Berkes 2014). Our research aims to systematically examine how art and artistic processes contribute to bridging of knowledge systems in two Inuit communities. We investigated in particular the mechanisms through which art and artistic processes enhance the process of bridging knowledge systems about social-ecological change. In turn, we contribute more broadly to understanding the relationships between art and artistic processes and resilience in the context of change and uncertainty.

\section{LITERATURE REVIEW}

An emerging literature is exploring the relationship between art and artistic process and social-ecological resilience, e.g., as reflected in this Special Feature titled Reconciling Art and Science for Sustainability. For example, the relationship between artists

${ }^{1}$ Environmental Change and Governance Group, University of Waterloo, ${ }^{2}$ Waterloo Institute for Social Innovation and Resilience, University of Waterloo 
and the environment has been explored in an Australian case study examining how artists harvest and utilize different species (Koenig et al. 2011). The capacity of art to communicate complex ecology has also been described (Curtis et al. 2012, Vervoort et al. 2014). Scholars have discussed the need to integrate aesthetics more rigorously into the process of scenario planning (Ramirez and Ravetz 2011), into governance (Armitage et al. 2014), and in how knowledge bridging is approached (Elgin 2002, Rathwell et al. 2015). For example, Maffie (2009:59) reflects on a case where a researcher may have learned much more had he heeded the words of his study subject, a Shinto priest: "We have no theology, we dance." Movement is the most compelling way the Shinto priest can share knowledge, and this example highlights the value of movement as a particular aesthetic form in conveying important meaning. Here, we augment this growing literature relating art and resilience by examining art objects and artistic processes as mediators to bridge knowledge systems about social-ecological change.

Creative methods for bridging knowledge systems that involve, for example, storytelling and oral history show promise in their capacity to engage with the many dimensions that make up knowledge systems, e.g., ontology, epistemology, axiology, methodology, and knowledge-practice-belief (Cruikshank 2005, 2012, Kunuk and Mauro 2010, Berkes 2012, Martin 2012, Cunsolo Willox et al. 2013, Fox Gerhard et al. 2013). Settings such as collaborative mural making (Zurba and Berkes 2014), collaborative art (Zurba and Friesen 2014), performance art (Heras and Tabàra 2014, 2015), and digital storytelling (Kunuk and Mauro 2010, Cunsolo Willox et al. 2013) all demonstrate how art-making and artistic processes can help participants to better understand each others' values in the context of changing social and ecological conditions.

Art and artistic processes can be conceptualized as "artistic boundary objects." As an extension of the boundary object concept (Star and Griesemer 1989), art and artistic processes promise to be particularly robust types of boundary objects (Singh 2011, Halpern 2012). Boundary objects connect social worlds and can help mediate knowledge bridging because they are "plastic enough to adapt to local needs, and the constraints of the several parties employing them, yet robust enough to maintain a common identity across sites" (Star and Griesemer 1989:393). Marsh (2012) describes working with aboriginal highschool students in their artistic process of hip-hop song writing. Through the process of creating hip-hop music, aboriginal youth are able to merge their Indigenous narratives with modern culture and find a hybrid voice to navigate their identity in turbulent times (Marsh 2012).

Aesthetic objects are also valuable because they foster settings for discussion and creation of shared stories, e.g., of change and/or responses to change (Pink 2001, Somerville 2013, Rathwell et al. 2015). In an Indigenous context, moreover, direct exposure to artworks is considered a form of decolonization because one is vulnerable to the cultural values and ideals reflected by the object (Schiwy 2003). For instance, Australian aborigines and researchers made a collaborative mural as a boundary object to communicate perspectives on how to care for their environment (Zurba and Berkes 2014). In another example, an Inuit carving (as an artistic boundary object) traveled from a small Inuit community to an international decision-making arena and is credited with bringing a humanity into the meeting and inspiring outcomes in favour of Inuit health and well-being (Johnson 2014, Watt-Cloutier 2015). An opportunity exists to better understand the underlying mechanisms of how art objects and art making function to mediate knowledge system bridging. We contribute to this understanding by drawing on the perspectives of Inuit artists, as well as through research projects in the form of a collaborative art process with youth, artists, and elders.

\section{STUDY LOCATION}

Cape Dorset and Pangnirtung, Nunavut, are two communities in Baffin Island, and they provide the context for this research (Fig. 1). Both communities are experiencing rapid social-ecological change from external drivers, such as sea ice loss from climate change that impacts the connection between people and the environment, e.g., no access to traditional hunting routes and food insecurity (Krupnik and Jolly 2002, Krupnik et al. 2010). External social drivers of colonization and globalization also have an impact on the social-ecological system of people, art, and nature in Inuit communities. For example, Inuit art as an economic commodity was introduced to these communities (Bagg 1997). Maintaining the resilience of traditional knowledge is an important challenge with the pressure of ecological and social drivers of change (ACIA 2005, Arctic Council 2013).

Fig. 1.Map of study region: Cape Dorset and Pangnirtung, Nunavut, are identified, as well as Iqaluit, the capital. Inset map shows study region relative to Canada.

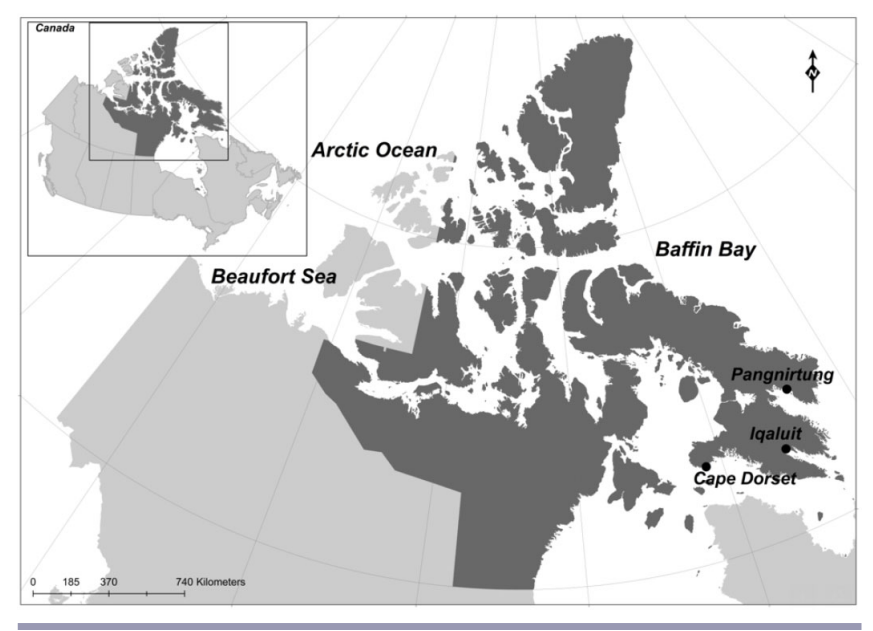

Pangnirtung is a community of 1510 residents nestled on a fjord between Auyuittuq National Park and Cumberland Sound. Pangnirtung, first a trading post for the Hudson Bay Company, acquired municipal government status in 1973. The main livelihood activities in Pangnirtung are subsistence hunting, working at the fish plant, art and craft making, and municipal and territorial government services, e.g., water and sewage truck drivers, local nursing station, and Nunavut Health Services. Tourism is active in Pangnirtung, facilitated by the dramatic natural landscape and coastal access. Textile arts, carving, and printmaking are the prominent art forms practiced in Pangnirtung. 
Cape Dorset, with a current population of about 1400 residents, was established as a trading post to service the Hudson Bay Company and became a settlement in the 1950s. Art making is Cape Dorset's most important economic activity. The community calls itself The Capital of Inuit Art, with a reputation for artistic talent extending internationally (Hessel and Hessel 1998, Hamlet of Cape Dorset municipal website, http://www.capedorset.ca/en/ community.asp). Lithography, stone cutting, stencil, and etching are all techniques used for Cape Dorset prints. The annual Cape Dorset Print Collection is an opportunity to showcase selected works to a global arts audience. Pencil crayons and large-format paper are provided to graphic artists in the community; both inhouse artists and community artists sell drawings to the Kinngait art co-op to be turned into prints or for direct shipment south. Carving with power tools is the other most prominent art form in the community. Plans are emerging for a world-class art center in Cape Dorset, which would provide many opportunities to foster the talent of individuals in this community. Cape Dorset and Pangnirtung were chosen specifically because of the legacy of art making in these communities (Hessel and Hessell 1998).

The art co-op is a center of activity in Cape Dorset. During work hours, artists fill the Kinggait print studio and attached art coop. Inside the art studios, artists are drawing, etching, and printmaking while working in pods. At peak hours carvers are lined up at the entrance with the hopes of selling their recent work to the co-op (Mangaard 2010) for shipment and sale in the south of Canada. Some artists continue to draw or carve during the evenings and weekends. While walking the streets, one hears the soundtrack of power tools omnipresent as carvers work constantly beside houses. Cape Dorset Fine Arts, a for-profit organization based in Toronto, facilitates the interaction between the local-scale art making and the national and international art culture.

The first author spent four months in Pangnirtung and six weeks in Cape Dorset during the summer and fall of 2013. The time spent building friendships and trust with community members was pivotal to the success of our project (see Wolfe et al. 2007, Castledon et al. 2012) and has helped to foster the legitimacy and contribution of the project. For example, the collaborative mural project was created at the request of employees and volunteers of the local youth center. Realization of the mural took a time span of three months. Our mural activities and research interviews echoed the participants' changing priorities. An adaptive approach to participatory projects enhances research in an Inuit context, because participants' interests are respected and accounted for in project plans and time lines (Wolfe et al. 2007, Castleden et al. 2012). For example, following the sudden death of a beloved community member, the mural project was put on hold. In another example, a carver who was happy to meet for an interview was no longer available because the narwhals were passing the bay, providing an opportunity to hunt.

Local community members, e.g., youth leaders, art co-op managers, and research assistants, were pivotal to the project. Enhancing local capacity by engaging community members in research was a way to add social value to the work, and this is consistent with expectations of researchers in the north (see ACUNS 2003). Community researchers were hired for organization and translation based on recommendations from scholars and community leaders. Lists of practicing artists in each of the communities were compiled based on advice from community researchers, art co-op managers, local artists, and community leaders, as well as Internet and paper resources, e.g., print shop catalogues. Community researchers were also experts in local geography and advisors about local politics and customs. Having the help of these local experts facilitated the research in many important ways. For example, one community researcher knew where each of 20 Cape Dorset artists lived and created mental maps for our day's walk around the community to do house visits and interviews. Similarly, a local youth leader leveraged her social network ties to help increase youth participation in workshops during mural creation. The contributions of community researchers and other supportive individuals significantly enhanced the flow, rigor, and outcome of our work.

\section{METHODS}

Three data collection methods were used in this research: (1) semistructured interviews about the role of art in the lives of individuals in the community and as a medium to reflect experiences with environmental change; (2) facilitation of, and engagement with, participatory art that included two workshops and three months of stenciling, painting, sewing, and framing to create the mural; and (3) participant observation during five months spent in Pangnirtung and Cape Dorset, Nunavut. We used these three sources of evidence to better understand how art and artistic processes can mediate knowledge system bridging in these communities.

A total of 30 professional artists were interviewed. "Professional" in this case indicates obtaining at least a portion of income from artworks. Our semistructured interview guide allowed for conversational (Kvale 1996) and storytelling tangents, especially with elders, as is respectful to Inuit culture (Martin 2012). Interviews were conducted in Inuktitut or English depending on the participant's choice. Length of interviews varied between 20 minutes and 2 hours. All participants were given an honorarium of CAD $\$ 100$ for their time, as suggested by northern researchers and the Nunavut Research Institute. In some cases, artists had artworks present during interviews to help with descriptions, and in others they remembered an artwork and described it orally. Interviews were crucial to gain the perspectives of local artists.

In addition to the insights about art and artistic processes gained from interviews with Inuit artists, the lead author designed and cofacilitated two workshops and helped make a collaborative mural with other youth, artists, and Inuit elders. The mural project offered an opportunity to focus on process. We were interested in if/how our interactions and the experience of making and sharing art during mural creation created opportunities for bridging knowledge about social-ecological change. With the mural project, we were able to identify similarities between what artists identify as the role of art and how that role manifests in practice. Follow-up interviews with participants in the collaborative mural, including youth and elders, enhanced our analysis. Only youth older than sixteen years of age were interviewed.

We used social-ecological change as an organizing theme for our mural project. Mural creation lasted for three months, from July 2013 to October 2013. The mural creation process included planning the process, garnering local support and priorities, two 
workshops involving storytelling, ongoing art-making activities at several venues (e.g., print shop, art studio, elders' homes), and a final celebration with the community. We organized a series of games and invented a method of imagery coconstruction for the mural process. We planned a full-day workshop and one half-day workshop with advice from local experts about how to engage youth. During the first workshop six Inuit youth and three southern youth wrote on two small cards: (1) something old and (2) something new. Sitting in a circle, we told a story about the something old or something new on our card while the person to our left quickly sketched a vignette image of the story. After two hours of stories and sketching, we discussed as a group common themes and ideas for how to synthesize the images onto a mural (see sketches in Fig. 2). The broader story is about connecting to the land in a historical context and in a present-day context. In a second workshop, we used the mural as a starting point to engage elders in storytelling about sea ice (workshop action photo, Fig. 3). We followed the same method of stories and sketches, but focused on the stories of participating elders.

Fig. 2. Photo of youth skteches created during the first workshop.

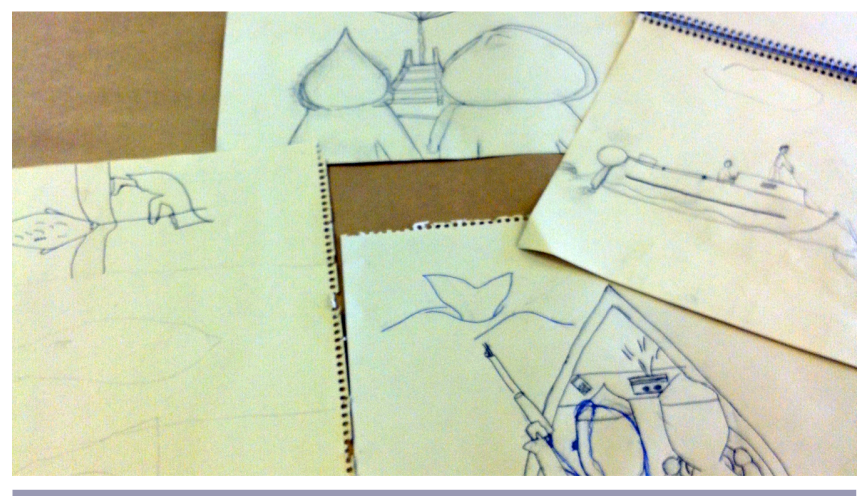

Fig. 3. An action photo from our second workshop with Inuit youth and elders. Youth are sketching, while elders are sharing stories about experiences with the sea ice.

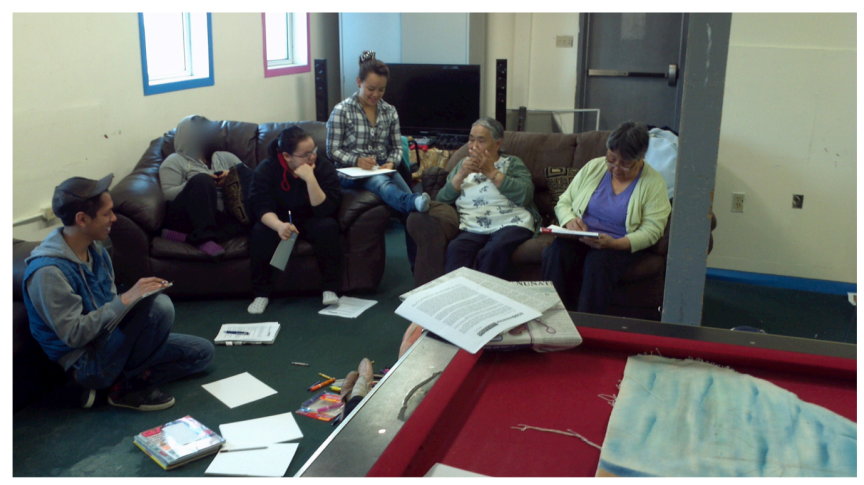

The mural project had community and regional support. The municipality of Pangnirtung, Nunavut, provided both in-kind support (e.g., connections to the youth Making Connections coordinator and her team) and financial support (\$500 to have a professional local artist provide instruction and encouragement to youth). The project was featured in the northern regional newspaper (Dolphin 2013). Although some of the art making for the mural was formalized, for example, painting at the local print shop with a lesson from a printmaker, other aspects were more informal. We carried the canvas mural to elders' homes for help with sewing sealskin accents onto the mural and for help mounting the mural on a traditional wooden frame. As facilitators, we strived to create stability and availability, and aimed for flexibility in working with all participants. For example, being in the print shop working for several hours offered youth an opportunity to come and work on the mural when they were ready and for as long as they wanted.

Interviews were transcribed, and open coding was performed on all transcripts. Detailed field notes were not coded but functioned to contextualize the themes identified during interview coding. Follow-up interviews with mural participants adhered to the same protocol and were cross-checked with themes from artist interviews. Coding was done manually. Open coding established main themes. These themes became row headings in an Excel spreadsheet. Every time evidence for a theme came up in an interview, the specific quotes from that interview were added to the row of evidence for that theme. Artists and mural participants were each assigned a column, creating a large data matrix. Interviews were rechecked once new themes became apparent (see Oktay 2012).

Ethics approval for this research was obtained through the University of Waterloo Office of Research Ethics (ORE \#19045). In addition, a research license was obtained through the Nunavut Research Institute (\#01027 13N-M). The process to obtain the Nunavut Research Institute license involved consulting with relevant community interests prior to the submission of the application and modifying the application to reflect the interests and concerns of the communities. This research process has endeavored to be transparent, inclusive, and empowering for participants and the communities. The identities of the individuals that participated in the research have been maintained as per the Office of Research Ethics consent process:

In an interview study with visual artists concerning some
aspect of the way they work, it might be appropriate and
respectful to identify the respondents. If failing to
identify participants would be unethical because of any
disrespect it would represent, or if informed participants
assert their desire to be named, then researchers should
do so, according to the practices of their discipline.
(Chapter 10 of Tri-Council Policy Statement)

Participants were asked to give written consent for their name to be used in this research. All agreed to do so.

\section{RESULTS}

Our results show that artworks and art making support Inuit knowledge and enhance opportunities to bridge this knowledge across cultures and generations. Specifically, we identified six key mechanisms through which art may support knowledge system bridging about social-ecological change:

1. Embedding knowledge, practice, and belief into art objects.

2. Sharing knowledge using the special language that is art. 
3. Art-making skills shared in practice.

4. Monitoring social-ecological change and anomaly.

5. Maintaining continuity over time in art and art making.

6. Knowledge coproduction/creation of hybrid knowledge.

Embedding knowledge-practice-belief into art objects

The mechanism of embedding knowledge-practice-belief (see Berkes 2012) into artworks describes art objects in their capacity to represent knowledge. Artists leverage symbolism and depictions of real-life scenes to reflect knowledge systems.

Artists generally speak of their works as objects that can depict knowledge. Key evidence to support this theme emerged from interviews with Inuit artists. For example, Jaco Ishulutaq shared that some of his carvings demonstrate "how one should live" (personal communication, August 2013; see Table 1). Here, a valueladen belief of his knowledge system is embedded into his carving. He described one carving titled Father and Son Forgive Each Other With a Hug. The carving demonstrates that one should live by forgiving others. Several artists also emphasized the art object being able to communicate practical components of knowledge that are required for survival in the north. Tainya Nowdlak (personal communication, September 2013) described how her hand-sewn sealskin boots called kamiks "tell a story of how one has to work with the sealskin." Often the art object is described as having the role of embedding lessons so that younger generations can learn. Elisapee Ishulutaq, from Pangnirtung, describes how artworks can enhance connections between elders and younger generations and enhance the exchange of knowledge: "Having some sort of visual aid like art would really put a clearer picture into what the elders are trying to say" (personal communication, August 2013, see Table 1). Thus, many participants in the research illustrated how art objects can facilitate knowledge system bridging by acting as a knowledgepractice-belief artefact.

\section{Sharing knowledge using a special language}

Artists emphasized how the actions of art and art making serve as a special language that helps bridge knowledge, practices, and beliefs among Inuit (e.g., youth and elders) and among Inuit and non-Inuit people. This mechanism highlights an important relational aspect that emerges through the sharing of artworks and during collaborative art making processes.

Artists emphasized that a goal of their art making was to provide a unique opportunity to share stories and histories. For example, Elisapee Ishulutaq explained her initial incentive for making art as "to leave a footprint...to be able to share history through images" (personal communication, August 2013; see Table 1). Pitaloosie Sila expressed the same sentiment. She said, "I share my knowledge with my grandchildren, the traditional ways that I know, via the drawing" (personal communication, October 2013; see Table 1). Jolly Atagoyuk articulated that "kids will learn more" if artworks are also used to share Inuit tradition and knowledge (see Table 1 for full quotation). Madaline Oumauataq described how important symbols for Inuit identity are shared using the "special language" of her artworks (personal communication, August 2013; see Table 1). The $u l u$, for example, is a women's knife and functions as a symbol of female empowerment in Oumauataq's artworks. Artists emphasized the specific need to share Inuit knowledge with younger generations, and art and artistic processes as a means to do so.

\section{Art-making skills shared in practice}

Art making also bridges knowledge systems by offering an opportunity to share skills. The skills that are shared during art making can be related to the technique of artistic practice itself or knowledge or stories related to the phenomenon of interest, i.e., the subject matter of artworks. Artworks also can be lessons about how to treat each other during interactions.

Artists described how they learned art skills in practice by watching others, often family, work. For the majority of Inuit artists interviewed $(n=27)$, learning art skills occurred informally by watching family members at home, or similarly, in the carving shed beside the home. For example, Cee Pootoogook described watching his mother draw "almost every day" (personal communication, October 2013). In another example Toonoo Sharky described how "I learned by watching my grandfather, and I took his place trying to imitate his carving at that time" (personal communication, November 2013; see Table 1). Also, during the mural making, youth learned new skills about art making and traditional practice:

Ithink the mural helped us with a lot of things, like helped
all of us. It helped me [learn] how to sew better and how
to sew it onto the frame and tighten it... [Participating
in the mural project] helped me draw better and I learned
about hunting.... (Mary Angmarlik, personal communication,
September 2013)

The stories and legends told during the mural process helped participants reflect on a variety of themes important in their lives, such as hunting and maintaining skills that have cultural and economic importance.

Other participants also highlighted the skills and knowledge dimensions of the mural process. For instance, Eddie Perrier described how his preference is to use the art-making setting as an opportunity to learn about how the environment is changing. $\mathrm{He}$ described the situation in which one printmaker showed him the art techniques, while another printmaker described her knowledge about the phenomenon being drawn:

Jolly showed me how to draw icebergs and the mountains
[from] his perspective... I kind of wish Eena did more
on the mural because she is a really talented artist and
printmaker and she is the one who told me the stories
about...the snow on the mountains and about how the
glaciers are changing. Where Jolly was just showing me
how to draw it, not the story behind it. (Eddie Perrier
personal communication, September 2013)

Finally, the practice of art making was also highlighted by participants as a opportunity to learn how the Inuit treat each other. For example, Tainya Nowdlak reflected on the practice of sharing Inuit knowledge by demonstrating how an Inuk will help others to the best of her ability. When describing her experience working on the mural, she said: "That is an Inuit tradition that we have. Traditional knowledge is how to share and treat others in that way. We used to help and assist each other back then in order to survive" (personal communication, August 2013). We witnessed Ms. Nowdlak do this when she helped us learn how to sew the mural into a skin stretcher using traditional techniques. 
Table 1. Summary of mechanisms through which art and artistic processes support knowledge system bridging. Selected supporting quotes are provided. We describe when necessary context and synthesize the connection between the quotes and the mechanism underlying knowledge system bridging.

Mechanism for bridging knowledge systems

Selected supporting quotations from interviews with Inuit artists $(n=30)$ and participants of a collaborative mural process
Brief explanation of how quotes demonstrate the mechanism
Embedding knowledge-practice-belief into art objects

"[The kamiks, or traditional sealskin boots] tell a story of how one has to work with the sealskin" (Tainya Nowdlak, personal communication, August 2013).

"When I was young the ice was not dangerous...now its getting dangerous and through art, artists can get it out there, sharing that the ice is getting dangerous. Now a days hunters don't really listen to elders for their knowledge or wisdom and having some sort of visual aid like art would really put a clearer picture into what the elders are trying to say" (Elisapee Ishulutaq, personal communication, August 2013).

"I carve all sorts of things...some carvings depict how one should live life, and some on the climate change” (Jaco Ishulutaq, personal communication, September 2013).

Sharing knowledge using a special language of art and art making "In 1970 [I started making art]. The main reason for making art being that the future generations could see my work.... I would leave a footprint so to speak...to be able to share history through images" (Elisapee Ishulutaq, personal communication, August 2013).

"To keep it going, we can study more about art to pass on the traditional knowledge.... Our elder people are passing away. They drew most days...we can make a print out of these drawings to pass [the knowledge] on. This way young kids will learn more... In Nunavut we want to keep Inuit things alive" (Jolly Atagoyuk, personal communication, August 2013)

"Sharing Inuit culture and tradition: I can use a special language through my sewing and my painting... I have lots of ulus [in my artworks], like the mountains, they are something I am familiar with and something that [Inuit] woman have used for generations and generations...to achieve what she wants to do" (Madaline Oumauataq, personal communication, August 2013). "I share my knowledge with my grandchildren, the traditional ways that I know, via the drawing" (Petaloosie Sila, personal communication, October 2013).
Stitching and softening of the kamiks can be felt and studied by holding them.

Well-made kamiks keep feet warm while standing for hours in wet ice.

Art objects are visual learning aids.

Jaco Ishulutaq has carvings that leverage metaphor and symbol to embed a value message about "how one should live life."

Elisapee Ishulutaq emphasizes how her artworks allow her to share history through images with future generations. Artists emphasize traditional knowledge and traditional ways to be what is important to share using art and artworks.

Engaging with art (studying, sharing) is one way artists approach maintaining traditional knowledge in Inuit communities

Artists are especially interested in sharing knowledge with younger generations.

The $u l u$ is a traditional Inuit women's knife. A woman carries the $u l u$ with her and uses it for cutting food, skins, ice etc.

Art-making skills shared (in practice)

"I actually learned from my mother, she used to draw almost every day. I used to live with her... would sometimes help her with etching, when she needed help...." (Cee Pootoogook, personal communication, October 2013).

"I learned by watching my grandfather and I took his place trying to imitate his carving at that time" (Toonoo Sharky, personal communication, November 2013).

"I think the mural helped us with a lot of thing.... It helped me [learn] how to sew better and how to sew it onto the frame and tighten it... [Participating in the mural project] helped me draw better and I learned about hunting and a lot of stuff" (Mary Angmarlik, personal communication, September 2013).

"Jolly showed me how to draw icebergs and the mountains that is his perspective.... I kind of wish Eena did more on the mural because she is a really talented artist and printmaker and she is the one who told me the stories about how the snow on the mountains and about how the glaciers are changing. Where Jolly was just showing me how to draw it, not the story behind it." (Eddie Perrier personal communication, September 2013).

"What I can do and what I do, I try to assist and help others when needed. That is an Inuit tradition that we have. Traditional knowledge how to share and treat others in that way. We use to help and assist each other back then in order to survive" (Tainya Nowdlak, personal communication, August 2013).

Monitoring social-ecological change and anomaly

"When the ice forms later, I try to do the best work I can...talking through art about the climate changing...the ice breaking up on the flow edge and people boating much later" (Tim Pitseolak, personal communication, October 2013).

"I have a large watercolor painting a couple weeks ago at the print shop. Painted the fjord where there use to be a lot of glaciers [and] now the glaciers are not there as much as they used to be. That is what I believe I'm showing in the painting" (Andrew Qappik, personal communication, August 2013).

"I noticed that when the sea ice melted, I began to draw a lot of belugas... There was a lot of belugas coming in... when there should have been ice on the bay.... But the ice was gone and the beluga whales came in right away when there was no ice there" (Papiara Tukiqi, personal communication, October 2013)

I Art making provides economic security Sharing the practice of art making is one way elders have inspired younger generations

Sharing skills in practice can also be an opportunity to at the same time discuss knowledge and belief.

Eena Angmarlik is a professional artist and assistant at the print shop in Pangnirtung.

Eddie Perrier draws our attention to the fluidity of knowledge for teaching and learning. He emphasizes how learning the skills to draw and print glaciers, and the stories about glacier change, at the same time are a desirable way for him to learn.

Learning how to treat each other is an important component of knowledge. During mural creation, in addition to artistic techniques, we learned how Inuit should respond and help each other with skills and talents when possible.

Artists draw observations of a changing environment Artists incorporate the human response to changing environment

A bridge is occurring between knowledge systems and the changing environment via the artworks Knowledge captured in artworks can be bridged with existing and future generations to better understand changing environments and how to navigate uncertainty 
Maintaining continuity over time in art and art making

"My grandmother was an artist too, my whole family are artists: Like my cousin is a printer, my cousin is a carver, my brother is a printer, my brother a carver... My grandmother won a governor general award for her prints, and my uncle won a governor general award too.... My father use to be a master carver, my uncle use to be a master carver too" (Oqituq Ashoona, November 2013).

"As for being an artist, it is important you know. When you have a family who is an artist for a long time and you do a second third generation of course it is important. That is where regeneration is coming from the family side as an artist" (Padlaya Qiatsuq, personal communication, October 2013).

"I'm capturing that transition with my art. But what I've noticed is that I keep putting an Inuk woman there with that amautiq... and I'm not sure why but she always creeps in there [laughs]. I think I'm very comfortable with that" (Madaline Oumauataq, personal communication, August 2013).

"You hear the legends of Sedna and if someone were to fall in the water Sedna would be the one to rescue you. To carry on that story that's why I carve those" (Jaco Ishulutaq, personal communication, September 2013)

Knowledge coproduction/creation of hybrid knowledge

"[The ice is] suppose to be like this, there is suppose to be lots of ice, but there is no ice.... What if there is no more ice in the future? What is going to happen? These are the questions I ask.... When southerners see the drawing they probably say, 'I know what you mean' and they know it is changing out there" (Cee Pootoogook, personal communication, October 2013).

"From time to time I reflect on that day together. If that was done more often I would like it.... It would be nice if there were this kind of activity. It would really help the younger generation.... Drawing highlights what you are learning or what you have in mind, and if you have questions.. The project how it was prepared and put together it looked like some stories and drawings were made...there was a lot of meaning in how different people drew impressions of the same story.... They were really brainstorming how to put particular ideas together." (Towkie Qarpik, personal communication, September, 2013)

"We all brainstormed and like everything we thought of, pretty much everything went on that mural. Like all of our ideas, not just one person" (Mary Angmarlik, personal communication, September 2013).

"I think that the outcome came out really good. I liked the colors I like how it was all put together and the finishing touches that Mary did, like the tassel. The tassel Eddie loves. Because I got to draw the Pang hat from working at the Uqqurmiut Centre and I didn't even think of that, that is such an awesome idea, I like that" (Eddie Perrier, personal communication, September 2013).
The identity and practice of art making itself creates continuity for some of the Inuit interviewed. Artists described being empowered by being part of an art legacy.

The amautiq is a traditional woman's parka. It has a pouch sewn into the back and an extra large hood to accommodate an infant. Subconsciously, Madaline Oumauataq creates comfort in the midst of transition by using a woman in an amatiq as a symbol.

Jaco Ishulutaq is carrying on the stories of Sedna, the underwater sea goddess, in his carvings. Social continuity is created with shared stories and myths.
Print making in Pangnirtung and Cape Dorset is a collaborative task. Some artists in Cape Dorset and Pangnirtung specialize in drawing, while others are experts at etching or print making with the initial graphics. Neegookooloo is a Cape Dorset artist. Cee Pootoogook is working as printmaker on a graphic design Neegookooloo created about sea ice break up.

Cee Pootoogook also extends the invitation for relating to a drawing about sea ice to southerners. He describes how upon seeing the drawing of sea ice breaking up, southerners could relate that the climate is changing. The second quotation is an excerpt from a follow-up interview with Towkie Qarpik, a Pangnirtung artist and elder. She discusses how the youth cocreated knowledge when they interpreted elders' stories in sketches.

\section{Monitoring social-ecological change and anomaly}

Art is a medium through which to explore social and ecological change. Of the 30 artists interviewed in the Cape Dorset and Pangnirtung, 16 of them described making artworks on the theme of climate change and/or sea ice change. Artists explained how their works mirror changing environments or depict a memorable social-ecological event in their communities. In this way, the artworks themselves monitor environmental change, environmental anomaly, and in some cases how humans adapt to these changes. Artworks then act as picture books that tell stories of an increasingly variable environment.

Tim Pitseolak, for example, said, "When the ice forms later, I try to do the best work I can...talking through art about the climate changing...the ice breaking up on the flow edge and people boating much later" (personal communication, September 2013). Here the artist embeds knowledge about how the environment is changing and how local people adapt to these changes into his artwork. In another example, Papiara Tukiqi talked about how she was inspired to draw a memorable event linked to Arctic sea ice change:

I noticed that when the sea ice melted, I began to draw a lot of belugas. There was a lot of belugas coming in... when there should have been ice on the bay.... But the ice was gone and the beluga whales came in right away when there was no ice there. (Papiara Tukiqi, personal communication, October 2013)

Papiara Tukiqi is documenting an anomalous event due to changes in sea ice (Table 1). Other artists create works that mirror the changing landscape. For example Andrew Qappik described his watercolor of the Pangnirtung landscape:

I have a large watercolour painting a couple weeks ago at the print shop. Painted the fjord where there used to be a lot of glaciers [and] now the glaciers are not there as much as they used to be. That is what I believe I'm showing in the painting. (Andrew Qarpik, personal communication, August 2013)

\section{Maintaining continuity over time in art and art making}

Artworks and art making create continuity in one's identity that extends through many generations. Eight artists in Pangnirtung and Cape Dorset described how their role as an artist is part of an intergenerational legacy. Oqituq Ashoona proudly described how he is embedded in an intergenerational web of award-winning artists:

My grandmother was an artist too, my whole family is artists: Like my cousin is a printer, my cousin is a carver, my brother is a printer, my brother a carver... My grandmother won a governor general award for her prints 
and my uncle won a governor general award too.... My father used to be a master carver, my uncle used to be a master carver too. (Oqituq Ashoona, November 2013)

In another example, Padlaya Qiatsuq spoke explicitly about the importance of maintaining regeneration of artists in his family:

\section{As for being an artist, it is important you know. When you have a family who is an artist for a long time and you do a second third generation, of course it is important. That is where regeneration is coming from the family side as an artist (Padlaya Qiatsuq, personal communication, October 2013).}

Artists also use symbols in their artworks to maintain continuity of Inuit identity. For example, Madaline Oumauataq described her artwork on the theme of transition and the role the woman in an amautiq (traditional woman's parka) who keeps "popping up":

I'm capturing that transition with my art. What I've noticed mainly in each painting that I've done now, is that I keep putting that Inuk woman there with that amautiq, and I'm not sure why but she always creeps in there. hahaha! I think I'm very comfortable with that... I have lots of ulues [in my artworks], I really do. Again, like the mountains, it's something I am familiar with and it's something that a woman has used for generations and generations that has helped to build a family. To cut something, whatever it might be...food, material. It is an aid that really helps a woman to achieve what she wants to do. (Madaline Oumauataq, personal communication, August 2013)

The woman's parka and knife, amautiq and $u l u$ in Inuktitut, are traditional tools and also function for artists as symbols for the Inuit ways of life. Artists emphasized the importance of maintaining these symbols in their artworks to create continuity, understanding, and identity, and therefore, as symbols of tradition and empowerment. Even when the content of the artwork is transformation, as described above, these traditional symbols create continuity in the social-ecological system identity.

Artists recounted that maintaining myths and legends is an important role of art in their communities. For example, Jaco Ishulutaq described how he carves Sedna, the underwater sea goddess who protects and helps Inuit by providing sea mammals to eat, to carry on her story. Indeed, continuity in imagery was also evident during mural creation. When describing the old and new during our workshops, a central theme was people's connection to the land and animals. Youth emphasized this connection when speaking both about the past and about the present and future. Being on the land was, as a result, chosen as a main theme to be represented throughout the mural. The human-animal-land connection is a consistent framework for seeing the world that shapes Inuit people's experience and that is expressed artistically.

\section{Knowledge coproduction/creation of hybrid knowledge}

Collaborative art making is a platform for knowledge coproduction, whereby novel ideas or products emerge from different ways of knowing. Outcomes of knowledge coproduction create an understanding of a particular situation or context that is more rich than any individual perspective alone can provide (Riedlinger and Berkes 2001, Armitage et al. 2011).

Evidence that art making offers opportunities for knowledge coproduction and the creation of hybrid knowledge comes from both our interviews and our experiences collaborating with others on the art mural. Towkie Qarpik, an elder and artist who participated in one art workshop, reflected on how she saw art making create space for knowledge sharing and the creation of a hybrid mural (see also Table 1):

...Drawings or prints, they highlight particular
impressions about what it is like to be up here and they
have a meaning. The mural project, how it was prepared
and put together, it looked like some stories and drawings
were made and there was a lot of meaning in how different
people drew impressions of the same story. They were
really brainstorming how to put particular ideas together.
(Towkie Qarpik, personal communication, October 2013)

Towkie Qarpik is referring to how each youth participant drew a sketch while she was telling a story about travelling on the sea ice in her younger days, and she noticed that youth created new meaning. When discussing each image, youth participants placed an emphasis on parts of the story that connected with their own experiences on the land, putting the same story together in different ways and creating a hybrid mural by linking their own experiences with elders' stories.

Youth participants illustrated opportunities for knowledge coproduction during the collaborative mural process and recognized the mural itself as a hybrid art object. Mary Angmarlik (personal communication, September 2013) described how everyone's ideas were welcomed and included: "We all brainstormed and like everything we thought of, pretty much everything went on that mural. Like all of our ideas, not just one person's" (Table 1). These opportunities to learn were enhanced by being open and accepting to building on each other's ideas and finding ways to complement ideas and imagery. While discussing the common themes, we identified the significance of the humannature connection as a consistent thematic foundation for the mural. Together, participants decided and discussed how the images would be put together to tell a story, the whole of which is more compelling than any individual sketch (close-up of mural, Fig. 4)

Fig. 4. A close-up photo of the mural before completion.

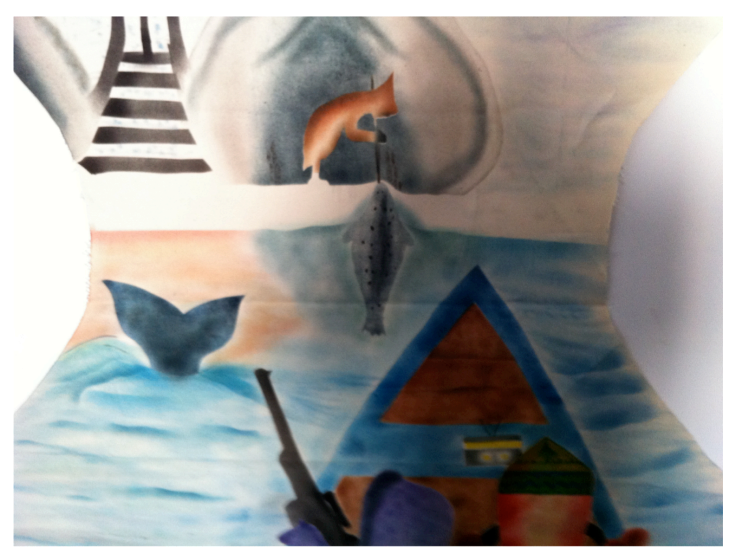


Combining material forms, e.g., sealskin, ink, and fabric, and using different artistic techniques also required a hybrid approach to the mural process. We were open to ideas and contributions of each participant, and many materials were available to work with. When reflecting on the mural, one participating youth, Eddie Perrier, commented on how a fellow participant, Mary Angmarlik, took initiative to add a fabric tassel to the stencilled hat depicted on the mural. The spirit of knowledge coproduction is evident in the quote below, in which Eddie describes how the outcome is better than what he could have thought of on his own:

I liked the colors. I like how it was all put together, and the finishing touches that Mary did, like the tassel... I got to draw the pang hat from working at the Uqqurmiut Centre and I didn't even think [to sew on a tassel]... hat is such an awesome idea, I like that (Eddie Perrier, personal communication, September 2013).

Knowledge coproduction is also mediated in these communities by the collaborative nature of printmaking. Different expertise and skills are required at each stage of printmaking, and these include drawing the graphic art, etching the graphic arts onto stone or metal plates, and finally, using the etched plates to create prints with ink and printmaking equipment. Sometimes artists have expert skill in only one of these stages. Therefore, an opportunity exists for knowledge coproduction and the creation of hybrid objects during the printmaking process. Similarly, sharing of artistic perspectives encouraged sense making about the environmental change reflected in the art. For example, working at the print shop in Cape Dorset, Cee Pootoogook described how he interacts with a drawing about sea ice breakup by another artist named Ningeokuluk Teevee. Below is a short excerpt from our interview:

Q: Right now you are working on a print by Neegookooloo? It is about the ice breaking up. When you are working on that, do you think about the sea ice? A: Very much yes.

Q: What sorts of things were you thinking about?

A: That [the ice is] supposed to be like this, there is supposed to be lots of ice, but there is no ice... What if there is no more ice in the future? What is going to happen? These are the questions I ask.... When southerners see the drawing they probably say, "I know what you mean" and they know [the environment] is changing out there. (Cee Pootoogook, October 2013)

Cee Pootoogook described how working with a drawing about sea ice breakup stimulates his own reflections on change and what it may be like in the future. The perspectives of both artists and each of their reflections made it into the final print, for example, in color nuance, texture, and point of view. Cee Pootoogook also reflected on how the art object can bridge Inuit perspectives with southerners' ideas about changing environments. He extended the capacity of artworks to stimulate knowledge coproduction beyond the artistic process, and with regards to the final print, felt that southerners could relate to the changing environment represented in the print through their own experiences of a changing environment. The message in this example is that for Inuit artists, art making becomes an opportunity to combine knowledge, to create hybrid knowledge and objects, and to use those objects to support knowledge sharing.

\section{DISCUSSION}

Our results show the underlying capacities of art objects and art making to bridge knowledge systems through time and space. In doing so, art and art making contribute significantly to nurturing resilience in social-ecological systems. The six mechanisms through which art and artistic processes support bridging knowledge systems identified here are not exhaustive. In addition, relationships and feedbacks exist among the six mechanisms we identified. Nevertheless, our categorization of mechanisms is a useful framework for further study and analysis, and as a way to conceptualize the many functions of art objects and art making. As such, we have offered empirically derived insights about some of the mechanisms through which art and artistic processes support bridging knowledge systems about social-ecological change.

Art and artistic processes are increasingly recognized for their role in helping to foster individual and community resilience in the context of change and uncertainty (Vancouver art Gallery 2006, Goldstein 2008). Based on our empirical research, we reflect here on how art objects and art making enhance resilience. In doing so we draw on two commonly articulated themes or dimensions of linked social-ecological resilience (see Walker et al. 2004, Folke et al. 2010):

1. Maintaining identity despite change and transformation (e.g., sea ice change, imposition of southern values on art and art making).

2. Increasing capacities (of individuals, communities) for learning and adaptation.

\section{Maintaining identity despite change and transformation}

Art objects and artistic processes are described by Inuit artists as helping to maintain continuity during times of change. In the current situation of rapid climate change occurring in the Arctic (ACIA 2005, Lenton 2012), Inuit artists reflect their impressions and observations of change and transformation in their artworks. At the same time, several artists spoke about embedding traditional knowledge-practice-belief into artworks. Papiara Tukiqi described the time when she drew belugas swarming the bay during an early sea ice melt (Table 1). Andrew Qappik spoke about painting the Pannirtung fjord to exemplify the glacier melt, and Madeline Oumauataq described embedding the amautiq, the Inuit women's parka with space for an infant in the back, into her artworks about transformation (Table 1). The amautiq and ulu (women's knife) are important for the female Inuit identity, for supporting women in nurturing and supporting a family. Although her subject matter itself is transformation, Ms. Oumauataq maintains continuity in her art using symbols paramount to the Inuit identity. Artists intentionally embed knowledge about how to hunt into artworks, noting that younger generations need more sources of knowledge because they don't know as much about hunting as their ancestors. Strengthening existing knowledge, traditional ways, and Inuit culture is emphasized by artists as a reason they make art. A strong sense of tradition and identity can help individuals and communities to maintain important functions (e.g., hunting) and identity (being an Inuk) despite changes and uncertainty, such as from drastic sea ice change.

The capacity of art to maintain continuity in knowledge across generations is paralleled by stories from other Indigenous 
cultures. Jim Hart, hereditary leader of the Saangga.ahl Clan (Haida Nation) and also an artist, reflected on how carved totem poles helped his people navigate turbulent times by creating a stronghold of identity and meaning:

Our people, when they carved these pieces, they were survivors from the old sicknesses that were going around. We have pieces in collections today that are older then those days, and then when the sicknesses came around...the carvers that survived that, how they got together and worked on pieces to help record our history, and for us today to look at, to hang on to, to study, to talk about, because all that knowledge is in there. We look at [a piece], and study it, and talk to each other about it. If we're lucky, we have relatives that recognize the pieces and also know its history, even more so, and tell us the stories behind it. For us to have been able to learn from that, and to carry on from that... the amount of history that's in those things where you stand there and hang on to it, you're hanging onto all your history, your past histories. It's so important, the strength that comes through that. And the person that's standing there is the extension of all that history. (Jim Hart as quoted in Raven Travelling; Vancouver Art Gallery 2006:182)

This quote expresses the phenomenon of art offering cultural cohesion during periods of change. Artists carved the totem poles during "the old sickness," in other words, during a period of crisis when western settlers infected these First Nations peoples with diseases to which they had no immunity, e.g., smallpox. The totem poles provide Haida people an opportunity to remain connected to their socio-cultural past as they navigate social-ecological change, e.g., shifting forestry governance in the 1980s, grieving loss of communities from illness.

Similarly, the examples noted above from Pangnirtung and Cape Dorset draw attention to the capacity of arts to carry stories and identity across generations. Continuity, supported by art and artworks, enhances the capacity of people and communities to navigate complex environmental change while maintaining a sense of shared identity. In these examples, artworks are leveraged to maintain identity during periods of change and transformation.

Artworks, as aesthetic boundary objects, can be place-based artifacts that function to nurture local social-ecological resilience, as in the examples above. They can also move through social networks, from local to global levels, creating opportunities to strengthen local identity and voice in the context of global change and uncertainty. Indeed, the Inuit artists interviewed for this project spoke about their artworks sharing the Inuit perspectives beyond communities to global levels. Cee Pootoogook described how people from other communities may react to a drawing of sea ice change, reflecting on climate change: "When southerners see the drawing [of sea ice] they probably say, 'I know what you mean' and they know it is changing out there" (Cee Pootoogook, personal communication, October 2013). In this example, the art object is taken beyond its context of creation and used for learning and knowledge bridging more broadly, e.g., nationally.

This function of artworks allows for bridging of knowledge systems across space and time. In another example, a carving of an Inuit woman carrying a child was brought by human rights activist Sheila Watt-Cloutier to an international policy meeting about persistent organic pollutants in Montreal, Canada, leading up to the Stockholm Convention (Johnson 2014, Watt-Cloutier 2015). The Inuit carving was leveraged as a mobile art object to bring a sense of humanity into the meeting and to use the practice of gift giving and art to stimulate empathy surrounding how persistent organic pollutants affect Inuit people. The artwork is credited with helping to direct meeting outcomes in a positive direction by considering the health of Inuit communities:

Watt-Cloutier presented the carving to the lead UN negotiator, Klaus Töpfer, Executive Director of the United Nations Environment Program (UNEP), at a reception UNEP was hosting. Töpfer accepted the gift and then presented it in turn to John Buccini, who was chairing the negotiations "with the request that it be displayed during the negotiations as a constant reminder to the delegates of the significance and importance of our task" (Buccini 2003). The [carving] therefore became a representation of the health and environmental concerns of Inuit and other Arctic Indigenous peoples. It sat in front of Buccini for the rest of the week, making further appearances at press conferences and at subsequent negotiations in Geneva, Bonn, Johannesburg, and Stockholm. (Johnson 2014:170)

\section{Increasing capacity for learning and adaptation}

Art and artistic processes are particularly important in their role of enhancing youth learning by bridging knowledge and experiences of younger generations and elders. For example, Elisapee Ishulutaq said that "having some sort of visual aid like art would really put a clearer picture into what the elders are trying to say" (personal communication, August 2013). We experienced the emergence of opportunities for enhanced learning when making the collaborative mural. For example, one participant described how making art about the glacier change on the mural was a good opportunity to learn from elders, and from artists' knowledge and belief, about these changes (see Table 1). When attaching the mural to a traditional wooden frame, we learned the sewing technique necessary to stretch sealskins onto a frame. Hence, we had the opportunity to learn traditional skills and also how to adapt skills for new contexts.

Embracing an adaptive approach to mural making and combining different types of knowledge resulted in knowledge coproduction. Knowledge coproduction is one mechanism for learning and adapting to change (Armitage et al. 2011). A tangible example of coproduction, from our experience, is how the elders and youth combined knowledge and aesthetics to sew small sealskin accents on the parkas and kamiks worn by figures in the mural. The traditional skin-stretching techniques used to mount the mural also emerged as an outcome of the sharing of information and strategies among elders and youth (mural on stretcher, Fig. 5). In this instance, Indigenous knowledge about sealskin cutting and sewing was transferred onto an unfamiliar medium, our mural, but still provided an opportunity to share traditional sewing skills between elder and youth on a hybrid platform (e.g., global youth culture of murals, with elder knowledge of sewing sealskins). 
Fig. 5. Photo of the final mural.

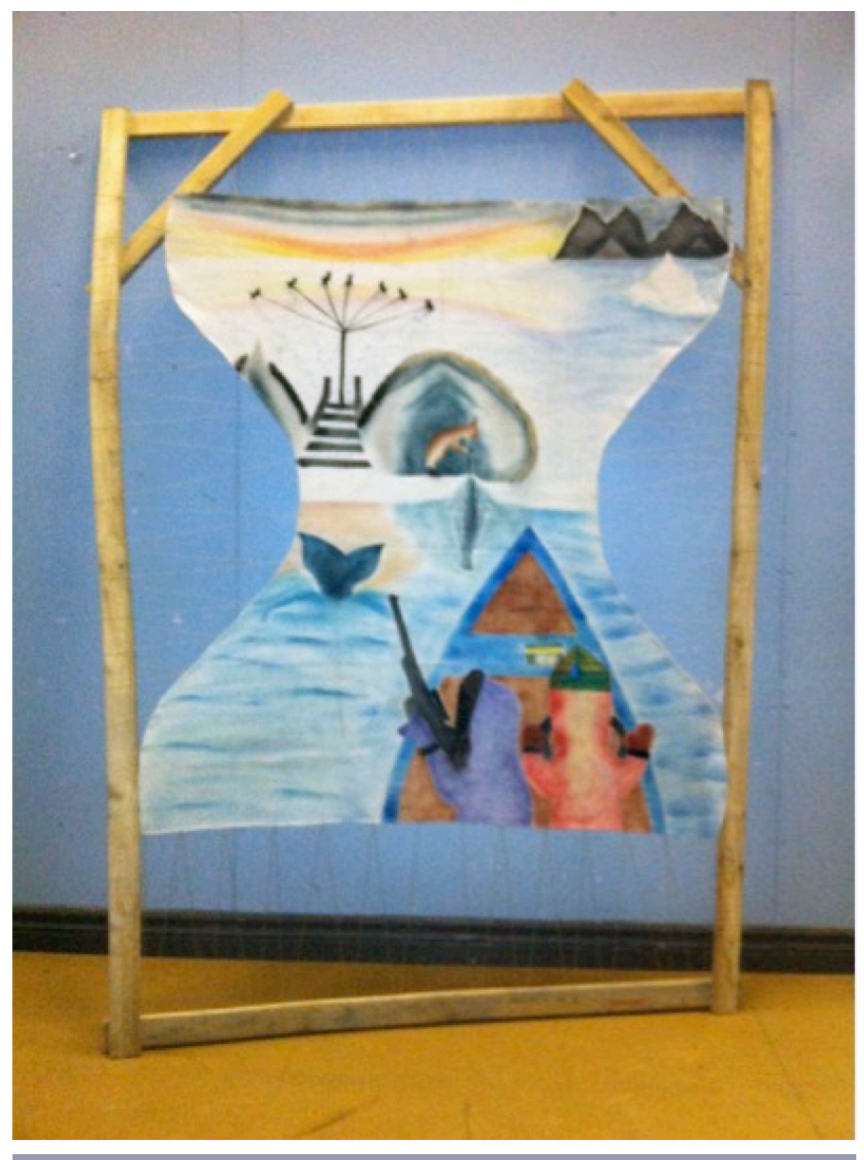

The hybrid mural outcome and process demonstrated that when Indigenous knowledge is being nurtured in creative processes, new hybrid forms of knowledge, ideas, and outputs emerge. The existence of these hybrid forms further strengthens Indigenous knowledge rather than diminishing it. Creative processes strengthen Indigenous knowledge by allowing it to be relevant to new contexts and in that way create opportunities to connect with youth. Traditional skills (e.g., cutting, sewing, stretching) were shared, in addition to less tangible aspects of knowledge systems. For example, the elders modeled how to contribute to the common good if you have skills and how to treat animals with respect when working with their skins.

\section{Synergistic role of art in Inuit communities}

Although the emphasis of this study was on how art and artistic processes function to bridge knowledge systems, we learned that art and art making have multiple roles that resonate with most artists. For example, art making provides income for families, embeds traditional knowledge into art objects, and creates an opportunity to bridge knowledge systems. Artists described opportunities to bond with grandchildren via questions and answers over artworks or sketches at the kitchen table (Table 1). The creation of such synergistic and positive outcomes suggests that investing in art and art making is a strategic choice.
When we asked artists openly about the role of art in their lives, the most common and immediate answer was that it provided income to support their family. A few examples are below:
It's really important in my life, given that there are hardly ever jobs to go around and everything nowadays in this world runs on money. Everything costs money... My main influence is for financial gain. There are no jobs.... I have kids and not all of them have jobs.... Every little thing costs money from food all the way to shelter. (Manasie Maniapik, personal communication, August 2013)
Well we don't have a job, the only way to make money, that's how we are trying to do something, like prints/arts something like that. Sealskin is like kinda, well Europe doesn't want to buy it anymore so we have to go with the carving, that's how we can make money. It's the only way, there are no other jobs. (Oqituq Ashoona, personal communication, November 2013)
I started when I got children, growing up little small children. I used to watch my father carve. It got into my mind that I could support my family through carving and that was my goal. (Omalluk Oshutsiaq, personal communication, October 2013)

Artists demonstrate adapting to external economic signals and drivers of change by creating artworks. Beyond providing economic security, a few artists remarked about the therapeutic benefits of artistic engagement. For example, Elisapee Ishulutaq said, "It can be therapeutic. If you have anxieties if you are doing art you are not thinking about your anxieties" (personal communication, August 2013). Madaline Oumauataq took this a step further and described how art making is a way to heal from intergenerational trauma:

The art helps with that process, just by remembering, just by drawing, by painting, by embroidering. Because when I am embroidering I remember my mother, if I remember my mother I remember my siblings; it's a common process, very common. Telling stories is a way of healing; it's a way of letting go of baggage that was not even yours to begin with. We have gone through such heavy changes in the last 40-50 years. Art is a way of making, not a new start, but using the old for the new, for the new life that we really should be celebrating again. (Madaline Oumauataq, personal communication, September 2013)

Art has multiple roles in these communities today, including providing economic security, as a form of therapy or healing, and for nurturing and mediating the bridging of Inuit knowledge. The emphasis of this paper has been on the latter. Our results show that art and artistic processes create positive synergies in outcomes.

\section{CONCLUSIONS}

Our study contributes to the emerging literature on the relationship between art and resilience. We consider enhanced resilience in the context of social-ecological change as an outcome of bridging knowledge systems via art and artistic processes. Bridging Indigenous and Western knowledge systems to navigate 
local to global social-ecological change is an important research and policy priority (Arctic Council 2013, Thaman et al. 2013, Tengö et al. 2014). Supporting local pockets of traditional ecological knowledge is important for both local and global resilience, to enhance understandings of change, and to create appropriate policy and practice (Gómez-Baggethun et al. 2013, McCarter et al. 2014)

Combining diverse knowledge systems for learning is relevant to resilience of social-ecological systems during change and uncertainty (Berkes et al. 2002, Reid et al. 2006). Our research highlights six underlying mechanisms through which art and artistic processes mediate knowledge system bridging: (1) embedding knowledge-practice-belief into art objects, (2) sharing knowledge using the special language that is art, (3) art-making skills shared in practice, (4) monitoring social-ecological change and anomaly, (5) maintaining continuity over time in art and art making, and (6) knowledge coproduction/creation of hybrid knowledge. These insights are important in continued efforts to bridge knowledge systems in the context of social-ecological change and to enhance individual and community resilience.

Responses to this article can be read online at: http://www.ecologyandsociety.org/issues/responses. $\mathrm{php} / 8369$

\section{Acknowledgments:}

Local research assistants and translators P. T. (Jojo) Aningmiuq, A. Kilabuk, and $O$. Oshutsiaq significantly enhanced our research project. Kaitlyn J. Rathwell would also like to acknowledge workshop cofacilitators L. Petersen and B. Hey, and youth leader M. Angmarlik. Kaitlyn J. Rathwell and Derek Armitage acknowledge research support from ArcticNet, the Northern Scientific Training Program (Aboriginal Affairs and Northern Development Canada), and a Social Science and Humanities Research Council of Canada grant to the Community Conservation Research Network. We appreciate the constructive feedback from two anonymous reviewers, as well as Fikret Berkes, Ian Mauro, and Sarah Wolfe, on an earlier draft.

\section{LITERATURE CITED}

Arctic Climate Impact Assessment (ACIA). 2005. Scientific report. Cambridge University Press, Cambridge, UK.

Arctic Council. 2013. Arctic resilience interim report. Stockholm Environment Institute and Stockholm Resilience Centre, Stockholm, Sweden.

Armitage, D., S. Alexander, M. Andrachuk, S. Berdej, T. Dyck, P. K. Nayak, J. Pittman, and K. Rathwell. 2014. Emerging concepts in adaptive management. Pages 235-254 in C. R. Allen and A. S. Garmestani, editors. Adaptive management of natural resources in theory and practice. Springer, Dordrecht, Netherlands. http://dx.doi.org/10.1007/978-94-017-9682-8 13

Armitage, D., F. Berkes, A. Dale, E. Kocho-Schellenberg, and E. Patton. 2011. Co-management and the coproduction of knowledge: learning to adapt in Canada's Arctic. Global
Environmental Change 21:(3):995-1004. http://dx.doi.org/10.1016/ j.gloenvcha.2011.04.006

Association of Canadian Universities for Northern Studies (ACUNS). 2003. Ethical principals for the conduct of research in the North. Department of Indian and Northern Affairs, Ottawa, Ontario, Canada.

Bagg, S. 1997. Making art work in Cape Dorset. Carleton University Art Gallery, Ottawa, Ontario, Canada.

Barthel, S., J. Parker, C. Folke, and J. Colding. 2013. Urban gardens-pockets of social-ecological memory. Pages 145-158 in K. G. Tidball and M. E. Krasny, editors. Greening in the red zone: disaster, resilience, and urgent biophilia. Springer, Dordrecht, Netherlands. http://dx.doi.org/10.1007/978-90-481-9947-1 11

Berkes, F. 2012. Sacred ecology. Third edition. Routledge, New York, New York, USA.

Berkes, F., J. Colding, and C. Folke, editors. 2002. Navigating social-ecological systems: building resilience for complexity and change. Cambridge University Press, New York, New York, USA. http://dx.doi.org/10.1017/cbo9780511541957

Berkes, F., and N. J. Turner. 2006. Knowledge, learning and the evolution of conservation practice for social-ecological system resilience. Human Ecology 34:479-494. http://dx.doi.org/10.1007/ s10745-006-9008-2

Carolan, M. S. 2005. Society, biology, and ecology: bringing nature back into sociology's disciplinary. Organization \& Environment 18(4):393-422. http://dx.doi.org/10.1177/1086026605281697

Castleden, H., V. Sloan Morgan, and C. Lamb. 2012. "I spent the first year drinking tea": exploring Canadian university researchers' perspectives on community-based participatory research involving Indigenous peoples. Canadian Geographer 56 (2):160-179. http://dx.doi.org/10.1111/j.1541-0064.2012.00432.x

Cunsolo Willox, A., S. Harper, V. Edge, the 'My Word' Lab, and the Rigolet Inuit Community Government. 2013. Storytelling in a digital age: digital storytelling as an emerging narrative method for preserving and promoting Indigenous oral wisdom. Qualitative Research 13(2):127-147. http://dx.doi. org/10.1177/1468794112446105

Cruikshank, J. 2005. Do glaciers listen? Local knowledge, colonial encounters, and social imagination. University of British Columbia Press, Vancouver, British Columbia, Canada.

Cruikshank, J. 2012. Are glaciers 'good to think with'? Recognizing indigenous environmental knowledge. Anthropological Forum 22(3):239-250. http://dx.doi.org/10.1080/00664677.2012.707972

Curtis, D. J., N. Reid, and G. Ballard. 2012. Communicating ecology through art: what scientists think. Ecology and Society 17(2):3. http://dx.doi.org/10.5751/ES-04670-170203

Dolphin, M. 2013. Art used to connect generations: youth and elders in Pangnirtung carry on storytelling tradition. Northern News Services, Northern Lights Series. September 2, 2013. Yellowknife, Northwest Territories, Canada.

Dryzek, J. S. 2005. The politics of the Earth: environmental discourses. Second edition. Oxford University Press, New York, New York, USA. 
Elgin, C. Z. 2002. Creation as reconfiguration: art in the advancement of science. International Studies in the Philosophy of Science 16(1):13-25. http://dx.doi.org/10.1080/02698590120118792

Fazey, I., A. C. Evely, M. S. Reed, L. C. Stringer, J. Kruijsen, P. C. L. White, A. Newsham, L. Jin, M. Cortazzi, J. Phillipson, K. Blackstock, N. Entwistle, W. Sheate, F. Armstrong, C. Blackmore, J. Fazey, J. Ingram, J. Gregson, P. Lowe, S. Morton, and C. Trevitt. 2013. Knowledge exchange: a review and research agenda for environmental management. Environmental Conservation 40:19-26. http://dx.doi.org/10.1017/S037689291200029X

Folke, C., S. R. Carpenter, B. Walker, M. Scheffer, T. Chapin, and J. Rockström. 2010. Resilience thinking: integrating resilience, adaptability and transformability. Ecology and Society 15(4):20. [online] URL: http://www.ecologyandsociety.org/vol15/iss4/ $\underline{\operatorname{art} 20 /}$

Foucault, M. 1991. Governmentality. Pages 87-104 in G. Burchell, C. Gordon, and P. Miller. The Foucault effect: studies in governmentality. University of Chicago Press, Chicago, Illinois, USA.

Fox Gearheard, S., L. Kielsen Holm, H. Huntington, J. Mello Leavitt, and A. R. Mahoney, editors. 2013. The meaning of ice: people and sea ice in three Arctic communities. International Polar Institute, Montreal, Quebec, Canada.

Gearheard, S., G. Apipellee, and K. O'Keefe. 2010. The Igliniit project: combining Inuit knowledge and geomatics engineering to develop a new observation tool for hunters. Pages 181-202 in I. Krupnik, C. Aporta, S. Gearheard, G. J. Laidler, and L. K. Holm, editors. SIKU: knowing our ice: documenting Inuit sea ice knowledge and use. Springer, Dordrecht, Netherlands. http://dx. doi.org/10.1007/978-90-481-8587-0 8

Godfrey-Smith, P. 2003. Theory and reality: an introduction to the philosophy of science. First edition. University of Chicago Press, Chicago, Illinois, USA. http://dx.doi.org/10.7208/ chicago/9780226300610.001.0001

Goldstein, B. E. 2012. Introduction: crisis and collaborative resilience. Pages 1-16 in B. E. Goldstein, editor. Collaborative resilience: moving through crisis to opportunity. Massachusetts Institute of Technology, Cambridge, Massachusetts, USA.

Gómez-Baggethun, E., E. Corbera, and V. Reyes-García. 2013. Traditional ecological knowledge and global environmental change: research findings and policy implications. Ecology and Society 18(4):72. http://dx.doi.org/10.5751/ES-06288-180472

Gratani, M., E. L. Bohensky, J. R. A. Butler, S. G. Sutton and S. Foale. 2014. Experts' perspectives on the integration of Indigenous knowledge and science in wet tropics natural resource management. Australian Geographer 45(2):167-184. http://dx.doi. org/10.1080/00049182.2014.899027

Halpern, M. K. 2012. Across the great divide: boundaries and boundary objects in art and science. Public Understanding of Science 21(8):922-937. http://dx.doi.org/10.1177/0963662510394040

Heras, M., and J. D. Tabàra 2014. Let's play transformations! Performantive methods for sustainability. Sustainability Science 9:379-398. http://dx.doi.org/10.1007/s11625-014-0245-9

Heras, M., and J. D. Tabàra 2015. Conservation theatre: mirroring experiences and performing stories in community management of natural resources. Society \& Natural Resources http://dx.doi. org/10.1080/08941920.2015.1095375

Hessel, I., and D. Hessel. 1998. Inuit art: an introduction. Douglas \& McIntyre, Vancouver, British Columbia, Canada.

Johnson, N. 2014. Thinking through affect: Inuit knowledge on the tundra and in global environmental politics. Journal of Political Ecology 21:161-177.

Koenig, J., J. C. Altman, and A. D. Griffiths. 2011. Artists as harvesters: natural resource use by indigenous woodcarvers in Central Arnhem Land, Australia. Human Ecology 39:407-419. http://dx.doi.org/10.1007/s10745-011-9413-z

Koutouki, K., P. Watts, and S. Booth. 2015. The Canadian Arctic marine ecological footprint and free prior informed consent: making the case for Indigenous public participation through inclusive education. Review of European Community \& International Environmental Law 24(2):160-170. http://dx.doi. org/10.1111/reel.12119

Krupnik, I., C. Aporta, S. Gearheard, G. J. Laidler, and L. K. Holm, editors. 2010. SIKU: knowing our ice: documenting Inuit sea ice knowledge and use. Dordrecht, Netherlands. http://dx.doi. org/10.1007/978-90-481-8587-0

Krupnik, I., and D. Jolly, editors. 2002. The Earth is faster now: Indigenous observations of Arctic environmental change. Arctic Research Consortium of U.S., Fairbanks, Alaska, USA.

Kunuk, Z., and I. Mauro. 2010. Inuit knowledge and climate change. Isuma.tv, Montreal, Quebec, Canada. online: [URL] http://www.isuma.tv/hi/en/inuit-knowledge-and-climate-change

Kvale, S. 1996. Interviews: an introduction to qualitative research interviewing. Sage, Thousand Oaks, California, USA.

Leduc, T. B. 2011. Climate, culture, change: Inuit and western dialogues with a warming North. University of Ottawa Press, Ottawa, Ontario, Canada.

Lenton, T. M. 2012. Arctic climate tipping points. AMBIO 41 (1):10-22. http://dx.doi.org/10.1007/s13280-011-0221-x

Maffie, J. 2009. 'In the end, we have the Gatling gun, and they have not': Future prospects of indigenous knowledge. Futures 41 (1):53-65. http://dx.doi.org/10.1016/j.futures.2008.07.008

Mangaard, A. [director]. 2010. Kinngait: riding light into the world. Documentary video recording. Bravo! Canada, Toronto, Ontario, Canada.

Marsh, C. 2012. Bits and pieces of truth: storytelling, identity, and hip hop in Saskatchewan. Pages 346-371 in B. Diamond and A. Hoefnagels, editors. Aboriginalmusic in contemporary Canada: echoes and exchanges. McGill-Queen's University Press, Montreal, Québec, Canada.

Martin, K. 2012. Stories in a new skin: approaches to Inuit literature. Part of the University of Manitoba Press series: Contemporary Studies on the North. University of Manitoba Press, Winnipeg, Manitoba, Canada.

McCarter, J., M. C. Gavin, S. Baereleo, and M. Love. 2014. The challenges of maintaining Indigenous ecological knowledge. Ecology and Society 19(3):39.http://dx.doi.org/10.5751/ES-06741-190339 
Mitchell, R. B., W. C. Clark, D. W. Cash, and N. M. Dickson. 2006. Global environmental assessments: information and influence. MIT Press, Cambridge, Massachusetts, USA.

Nadasdy, P. 2003. Hunters and bureaucrats: power, knowledge, and aboriginal-state relations in the southwest Yukon. UBC Press, Toronto, Ontario, Canada.

Oktay, J. S. 2012. Grounded theory. Oxford University Press, Oxford, UK. http://dx.doi.org/10.1093/acprof:oso/9780199753697.001.0001

Pink, S. 2001. Doing visual ethnography. Sage, Thousand Oaks, California, USA.

Ramırez, R., and J. Ravetz. 2011. Feral futures: Zen and aesthetics. Futures (43):478-487.

Rathwell, K. J., D. Armitage, and F. Berkes. 2015. Bridging knowledge systems to enhance governance of environmental commons: a typology of settings. International Journal of the Commons. 9(2):851-880. http://doi.org/10.18352/ijc.584 http:// dx.doi.org/10.18352/ijc.584

Reid, W., F. Berkes, T. Wilbanks, and D. Capistrano, editors. 2006. Bridging scales and knowledge systems: concepts and applications in ecosystem assessment. Millenium Ecosystem Assessment. Island Press, Washington, D.C., USA.

Riedlinger, D., and F. Berkes. 2001. Contributions of traditional knowledge to understanding climate change in the Canadian Arctic. Polar Record 37(203):315-328. http://dx.doi.org/10.1017/ $\underline{\mathrm{s} 0032247400017058}$

Ruiz-Mallén, I., and E. Corbera. 2013. Community-based conservation and traditional ecological knowledge: implications for social-ecological resilience. Ecology and Society 18(4):2. http:// dx.doi.org/10.5751/ES-05867-180412

Schiwy, F. 2003. Decolonizing the frame: indigenous video in the Andes. Journal of Cinema and Media 44(1):116-132.

Singh, A. 2011. Visual artefacts as boundary objects in participatory research paradigm. Journal of Visual Art Practice 10(1):35-50. http://dx.doi.org/10.1386/jvap.10.1.35_1

Star, S. L., and J. R. Griesemer. 1989. Institutional ecology, 'translations' and boundary objects: amateurs and professionals in Berkeley's Museum of Vertebrate Zoology, 1907-39. Social Studies of Science 19(3):387-420. http://dx.doi.org/10.1177/030$\underline{631289019003001}$

Somerville, M. 2013. Water in a dry land: place-learning through art and story. Routledge, New York, New York, USA.

Tengö M., E. S. Brondizio, T. Elmqvist, P. Malmer, and M. Spierenburg. 2014. Connecting diverse knowledge systems for enhanced ecosystem governance: the multiple evidence base approach. AMBIO 45(5):579-591. http://dx.doi.org/10.1007/ $\underline{\mathrm{s} 13280-014-0501-3}$

Thaman, R., P. Lyver, R. Mpande, E. Perez, J. Cariño, and K. Takeuchi, editors. 2013. The contribution of Indigenous and local knowledge systems to IPBES: building synergies with science. IPBES Expert Meeting Report, UNESCO/UNU. UNESCO, Paris, France.
United Nations (UN). Declaration on the rights of Indigenous peoples. 2007. UN General Assembly Resolution A/RES/61/295, 13 September 2007. UN, New York, New York, USA.

Vancouver Art Gallery. 2006. Raven travelling: two centuries of Haida art. Douglas \& McIntyre, Vancouver, British Columbia, Canada.

Vervoort, J. M., D. H. Keuskamp, K. Kok, R. van Lammeren, T. Stolk, T. (A.) Veldkamp, J. Rekveld, R. Schelfhout, B. Teklenburg, A. Cavalheiro Borges, S. Jánoškóva, W. Wits, N. Assmann, E. Abdi Dezfouli, K. Cunningham, B. Nordeman, and H. Rowlands. 2014. A sense of change: media designers and artists communicating about complexity in social-ecological systems. Ecology and Society 19(3):10. http://dx.doi.org/10.5751/ ES-06613-190310

Walker, B., C. S. Holling, S. R. Carpenter, and A. Kinzig. 2004. Resilience, adaptability and transformability in social-ecological systems. Ecology and Society 9(2):5. [online] URL: http://www. ecologyandsociety.org/vol9/iss2/art5/

Watt-Cloutier, S. 2015. The right to be cold: one woman's story of protecting her culture, the Arctic and the whole planet. Penguin, Toronto, Ontario, Canada.

Weiss, K., M. Hamann, and H. Marsh. 2013. Bridging knowledge: understanding and applying indigenous and Western scientific knowledge for marine wildlife management. Society \& Natural Resources 26:285-302. http://dx.doi.org/10.1080/08941920.2012.690065

Wolfe, B., D. Armitage, B. E. Brock, M. A. Sokal, K. P. CloggWright, C. L. Mongeon, M. E. Adam, R. I. Hall, and T. W. D. Edwards. 2007. From isotopes to TK interviews: towards interdisciplinary research in Fort Resolution and the Slave River Delta, Northwest Territories. Arctic 60(1):5-87. http://dx.doi. org/10.14430/arctic267

Zurba, M., and F. Berkes. 2014. Caring for country through participatory art: creating a boundary object for communicating Indigenous knowledge and values. Local Environment 19 (8):821-836. http://dx.doi.org/10.1080/13549839.2013.792051

Zurba, M., and H. A. Friesen. 2014. Finding common ground through creativity: exploring Indigenous settler and Metis values and connection to land. International Journal of Conflict and Reconciliation 2(1):1-34. 